\title{
Experience of gender-based violence to students in public and private secondary schools in Ilorin, Nigeria
}

\author{
Olufunmilayo I. Fawole ${ }^{1}$, Olubunmi D. Balogun ${ }^{1}$ and Oladipupo Olaleye ${ }^{2}$ \\ Ghana Med J 2018; 52(2): 66-73 doi: http://dx.doi.org/10.4314/gmj.v52i2.1 \\ ${ }^{1}$ Department of Epidemiology and Medical Statistics, College of Medicine, University of Ibadan, Ibadan, Ni- \\ geria, ${ }^{2}$ Department of Health Promotion and Education, College of Medicine, University of Ibadan, Nigeria
}

Corresponding author: Dr. Olufunmilayo Fawole

E-mail: fawoleo@ymail.com

Conflict of interest: None declared

\section{SUMMARY}

Objective: To determine and compare prevalence of Gender based Violence (GBV) in public and private secondary schools students and to identify factors associated with experience of GBV by the students.

Design: Comparative cross-sectional survey of using a 60 item self-administered questionnaire.

Setting: Ten public and private secondary schools in Ilorin South Local Government area of Kwara State.

Participants: 640 students, (320 each) from public and private schools.

Main outcome variable: Prevalence and factors influencing experience of physical, sexual and psychological violence

Results: At least one form of GBV was experienced by $89.1 \%$ of public and $84.8 \%$ private schools students $(\mathrm{p}=0.32)$. Psychological violence was commonest type of GBV experienced (Public $-72.5 \%$ vs. Private - 69.2\%; $\mathrm{p}=0.37$ ), while sexual violence was least (Public $-41.4 \%$ vs. Private $-37.4 \% ; \mathrm{p}=0.3$ ). Females were less likely to experience physical violence (OR 0.3 ; 95\% CI 0.2-0.4) and psychological violence (aOR 0.6; 95\%CI 0.4-0.8). Students who were in a relationship and who had history of parental violence were more likely to experience sexual (aOR 1.7; 95\%CI 1.2-2.4) and aOR 1.5; 95\%CI 1.2-2.2) and psychological (aOR 1.3; 95\%CI 1.1-1.5 and aOR 1.3; $95 \% \mathrm{CI}$ respectively) violence.

Conclusions: GBV was a common experience of students in both groups of schools. Multi-disciplinary interventions emphasising ending physical and psychological violence among private school students and sexual violence in public school are recommended. Interventions that involve the parents, school authorities and students on nonviolence conflict resolution are urgently required. Parents and students who perpetrate violence should be referred for counselling.

Funding: Author funded

Keywords: Violence, Gender based violence, Violence exposure, Secondary School, Students

\section{INTRODUCTION}

Although violence at school is not a new phenomenon, there has been growing social and scientific concern about this problem in recent years. ${ }^{1}$ Violence among young people is an important public health issue and a universal problem. ${ }^{1,2}$ It contributes significantly to preventable morbidity and mortality for men and women across diverse cultures. ${ }^{3}$ Consequently, efforts to identify risk and protective factors have intensified. ${ }^{4}$ A growing number of studies on adolescents suggests that violent behaviour or the intention to use violence is associated with a number of contextual, individual, and situational factors. ${ }^{1,2}$ Most of these studies were in high income countries, however there is dearth of information on the factors promoting and militating against violence among young /persons in low income countries.
In most low income countries, many adolescents live in social environments where they are exposed to high levels of violence and victimization., ${ }^{3,4}$ Migration, urbanization, and modernization coupled with conflicts and wars have made the exposure to community violence and its perpetration high among the large youth populations of sub-Saharan Africa. ${ }^{5}$ When exposure to violence in the community, the media and the home is combined with a lack of modelling on non-violent conflict resolution skills within the family, the youth do not learn the skills or perceive the need to avoid the use of violence to resolve conflict. ${ }^{4,5}$ Thus, the youth grow up learning to become perpetrators and often have experienced multiple episodes of victimization by the time they are adults. ${ }^{4}$ 
Schools are an ideal site for recruiting young person's because a sizeable proportion of the Nigerian adolescents are enrolled in schools. ${ }^{6}$ Net primary school attendance rate in $2007 / 2008$ was $62.1 \%$, while secondary school attendance rate was $49.1 \% .^{7}$ The school has a primary socializing influence on adolescents and youths. ${ }^{8}$ Schools are well-respected local institutions, touching all families in a community regardless of socio economic status or income. The school system is also an area where much interpersonal violence may occur in the form of canning and bullying. ${ }^{6}$ Apart from its consequences on physical health, victims of violence reported performance difficulties including absenteeism, interrupted studies, inability to study and loss of selfconfidence. $^{9}$

In Nigeria only a few studies have addressed the scope and correlates of violence in young people in schools. ${ }^{10,11}$ The first ever nation-wide situational analysis survey of public school violence in Nigeria, revealed that physical and psychological violence accounted for 85 and 50 percent respectively of the total experience of violence against students. ${ }^{6}$ A study in Osun State Nigeria, reported that 60.6 and 59.9 percent of males and females respectively had experienced physical or psychological violence from other students in the last one year. ${ }^{11}$

However, these studies described the violence experience of students attending public secondary schools only. Hence, there is paucity of literature on student's experience of violence in private schools and on the types of violence these students experience. However, there has been a change in preference for private schools by most parents in pursuit of quality education for their children. ${ }^{6}$ The violence experience of male students has also not been fully studied. This study therefore addressed these information gaps and determined the experience of GBV among male and female students in public and private senior secondary schools in Ilorin.

\section{METHODS}

\section{Study setting}

The study was carried out in Ilorin South Local Government Area (LGA) of Kwara State. Ilorin South LGA is one of the three LGAs that make up Ilorin metropolis. Based on the 2006 census, the LGA had a population of approximately 208,691 inhabitants who are mainly of the Yoruba ethnic group. ${ }^{12}$ The LGA has 30 public and 25 private secondary schools. The public school comprises of 14 senior and 16 junior schools. The students' population of these schools ranged from about 500 to $1,000 \cdot{ }^{13}$

\section{Study Population}

The study population comprised of male and female secondary school students in senior secondary school (SSS) classes one, two and three from public and private schools. In Nigeria, secondary education runs for six years and comprises of a junior secondary education for three years and senior secondary for another three years, both running concurrently. ${ }^{6,13}$ The choice of senior secondary school students were based on ethical consideration and age. Older adolescents and youth have also been reported to be more vulnerable to GBV than their younger colleagues. ${ }^{3}$ The exclusion criteria were students who were absent from school during the study period, whose parents did not consent, or whom did not assent to participate.

\section{Study Design}

This study was a comparative cross-sectional survey. Sample Size - Sample size was calculated using the two sided test formula for comparing two proportions based on the assumptions that the proportion of persons 15-19 years who had experienced physical and sexual violence was $28.3 \%,{ }^{7}$ difference expected between the two populations was $5 \%$, power $80 \%$ and significance level of $5 \%$. A minimum sample size of 270 respondents was calculated. Also, a 10\% adjustment was made for nonresponse which resulted in a minimum of 300 respondents per group.

\section{Recruitment Procedure}

A four-stage stratified sampling technique was used. In stage one, from the list of public (14) and private (16) schools in Ilorin south LGA, five schools each were randomly selected by ballot. Hence, a total of ten schools were selected. In stage two, senior secondary school classes one, two and three were purposively selected from the schools. In each class, information about the actual students' population was obtained and this was used to calculate the proportionate sample size required from the class. In stage three, a list of all arms in each class was drawn up and half of the arms were selected by ballot. In stage four to ensure gender equity, students were stratified by sex by having separate lists for males and females students in the selected arm. Male respondents were chosen from the list of male students in the selected arm using systematic random sampling technique and the same was done to select the female respondents.

The study began with advocacy visits to the schools in February 2012. Meetings were held with the school administrators to discuss the study, and obtain their cooperation. 


\section{Original Article}

The schools authorities gave their commitment and the teachers were available to provide support when it was required.

\section{Study Instrument}

A 60-item semi structured interviewer administered questionnaire was used for quantitative data collection. The questionnaire had six components namely:- demographic characteristics, awareness, knowledge, perceptions, sexual behavior and self-reported experience of violent behaviours. The instrument built on questionnaires from previous studies on violence. ${ }^{6,14,15}$

Questions on experience of physical, sexual and psychological violence were asked by giving examples of such acts. To ensure validity and reliability of the survey data, the questionnaire was pre-tested on 30 students from a public and private school in Ilorin West LGA.

\section{Data Collection}

Eight trained interviewers conducted face-to-face interviews with the selected students. The interviewers comprised of four male and four females. To facilitate communication male interviewers interviewed male students, while female interviewers interviewed female students. The interviewers were trained over a period of three days by the investigators. Informed consent and respondents assent was obtained before data collection. The interviews took place in an empty classroom to enable the participants respond freely to questions asked. Each interview took about 60 minutes. Data collection was from March to May 2012. A total of 604 students were interviewed.

\section{Study Variables}

The outcome measures were: experience of physical, sexual, psychological and any one of the three forms of violence stated above. The WHO definition of violence was adopted. ${ }^{15}$ Physical violence was defined by at least one affirmative response on whether or not the respondent had been beaten, hit, slapped in the face, bitten, pushed, punched, grabbed, had arm twisted, had an object or acid thrown at them, or threatened with a dangerous weapon. Sexual violence referred to sexual harassment at school or at home, unsolicited touching of breast or buttocks, unwanted kisses, being forced to watch sexually explicit materials, attempt to rape (including by using drugs or charms), rape, being forced to perform a type of sexual act against respondents wish, being forced to engage in sex for money or material goods, and being forced to terminate a pregnancy. Psychological violence was defined as saying something to deliberately belittle spite, humiliate, intimidate or relegate the respondent.
It also included verbal abuses and curses including, making the respondent anxious or depressed..$^{15}$ Violence experience referred to violence which occurred in the last twelve months.

The explanatory variables were selected socio demographic characteristics and information on the family background of the respondents. The demographic variables included sex, age, class and religion, while the family background questions were parent's education and occupation. Class referred to the respondent's current level of schooling namely senior secondary class 1 , 2 or 3. A partner (boy or girlfriend) was defined as an individual of opposite sex with whom there was intimate and possibly sexual relationship. History of interparental violence in childhood was also assessed.

\section{Data Analysis}

Data processing, cleaning and analysis were done using SPSS (1998) version 18 software package. ${ }^{16}$ Univarite and bivariate analysis were done. $\mathrm{P}$ value of less than 0.05 was considered significant. The bivariate analysis involved using the Pearsons Chi-square test. For example the chi square test was used to compare the experience of physical, sexual and psychological violence between public and private school students. Logistic regression analysis was also done and variables that were significant on bivariate analysis were included in the final model, adjusted odd ratios were computed.

\section{Ethical Considerations}

The World Health Organization (WHO) Recommendations on Ethics and Safety for Research on Domestic Violence against Women was used as a guide. ${ }^{17}$ The Ethical Review Committees of the Kwara State Ministry of Education (KW/012/03/64) and the University of Ilorin Teaching Hospital, Ilorin (BF/12/479/95), gave ethical clearance. Written informed consent was obtained from each participant. For participants less than 15 years of age, written informed consent was obtained from the parents, in addition to the respondents assent. Participation was voluntary. Confidentiality and anonymity were maintained. Victims in need of help were referred to a youth friendly centre for support or the tertiary health facility for care.

\section{RESULTS}

\section{Socio demographics}

As shown in Table 1, equal numbers (302 each) of respondents were interviewed from the two groups of schools. Also, males and females were equal (151 each) in number. Forty six point seven percent of the male respondents were between the ages of 10 and 15 years, compared with $53.3 \%$ of the females who were in the same age bracket. 
There was no difference in the mean age of respondents from public and private schools $(15.9 \pm 1.8$ years vs. $15.8 \pm 1.7$ years, $\mathrm{p}=0.64$ ). Polygamous families were more common among public school students, while monogamous families were more common among the families of the students in private schools $(p<0.001)$. Many of the students came from homes were there was inter-parental violence (65.9\% in public versus $71.9 \%$ in private school students; $\mathrm{p}=0.11$ ).

Table 1 Students Socio-demographic Characteristics

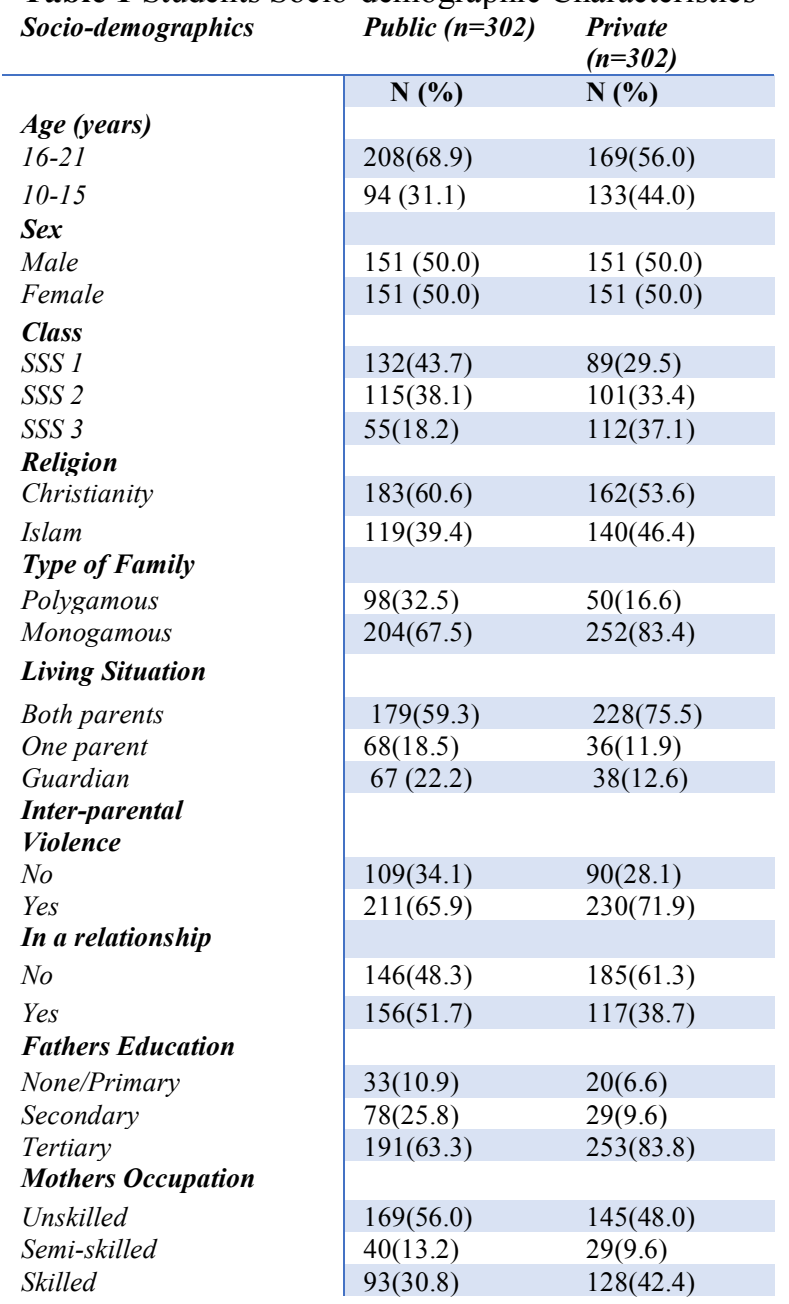

\section{Prevalence of experience of violence}

The prevalence of experiencing any of the three forms of violence was $84.8 \%$ and $89.1 \%$ in the public and private schools respectively $(\mathrm{p}=0.3)$. In both groups of schools, psychological violence ranked first $(59.2 \%$ vs. $72.5 \%, \mathrm{p}=0.03)$, physical violence was second $(67.2 \%$ vs. $70.2 \%, \mathrm{p}=0.3)$ and sexual violence ranked third (41.4\% vs $37.4 \%$; $\mathrm{p}=0.4$ ) (Table 2 ).
Experience of physical and psychological violence was significantly higher among male respondents $(54.4 \%$ vs $45.5 \% ; p=0.001$ and $54.7 \%$ vs. $45.3 \%$; $p=0.001$ in public and private students respectively), however experience of $(50.4 \%$ vs. $49.6 \%$; $\mathrm{p}=0.8)$ sexual violence was not significantly different between the sexes.

Table 2 Students' Experience of the Different Types of Gender Based Violence

\begin{tabular}{l|lll} 
Type of $G B V$ & Public & Private & $X^{2} ; p$ value \\
\hline & $\mathrm{n}=302$ & $\mathrm{n}=302$ & \\
Physical & $203(67.2)$ & $212(70.2)$ & $1.0 ; 0.3$ \\
Sexual & $125(41.4)$ & $113(37.4)$ & $0.6 ; 0.4$ \\
Psychological & $209(59.2)$ & $219(72.5)$ & $\mathbf{4 . 9} ; \mathbf{0 . 0 3}$ \\
Any GBV & $256(84.8)$ & $269(89.1)$ & $0.8 ; 0.4$
\end{tabular}

Table 3 Students Experience of Gender Based Violence by Type of School

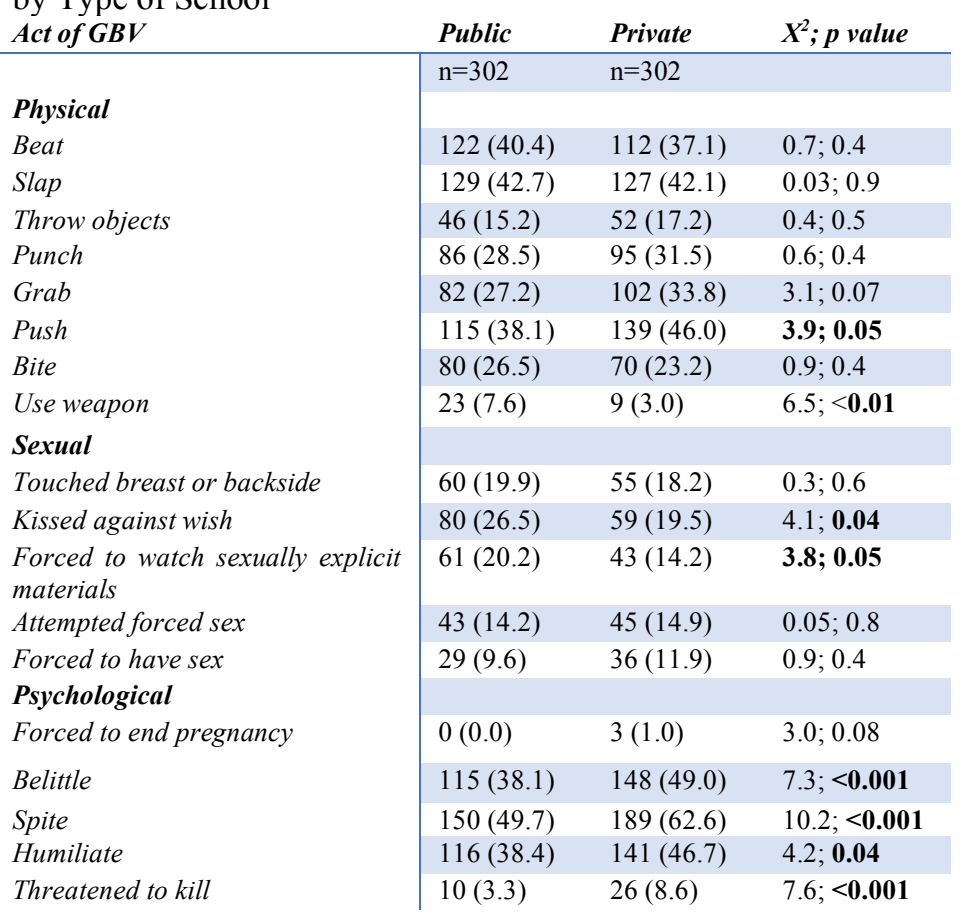

\section{Types of Violence Experienced.}

Physical: Table 3 show that slaps were the commonest form of physical violence experienced in public $(40.4 \%)$ and private schools $(37.1 \%)(\mathrm{p}=0.4)$.

Sexual: Shown in Table 3 is respondent's experience of sexual violence. In public schools unwanted kisses were the most common $(26.5 \%)$ form of sexual violence experienced and in private schools they were also the most common $(19.5 \%)(\mathrm{p}=0.04)$.

Psychological: Spite was the commonest form of psychological violence reported both in public and private school students $-49.7 \%$ and $62.6 \%$; $p=0.001$ respectively (Table 3). 


\section{Perpetrators of Violence}

The main perpetrators of physical violence included partners (boy/girlfriends) $(29.8 \%)$, friends $(51.1 \%)$ and family members $(16.1 \%)$; but friends were the commonest $(55.1 \%$ and $47.1 \% ; \mathrm{p}=0.2)$ in both groups of students.
Perpetrators of forced sex in both public and private schools were mainly partners $(85.7 \%$ and $80.9 \%$ respectively; $p=0.4)$. The major perpetrators of psychological violence were friends $(40.2 \%$ and $36.7 \% ; \mathrm{p}=0.1)$, followed by family members $(33.4 \%$ and $28.0 \% ; \mathrm{p}=0.8)$ in public and private schools respectively.

Table 4 Factors Influencing Students Experience of Gender Based Violence

\begin{tabular}{|c|c|c|c|c|c|}
\hline \multirow{2}{*}{$\begin{array}{l}\text { Socio-demographics } \\
\text { Location }\end{array}$} & Physical & \multicolumn{2}{|c|}{ Sexual } & \multicolumn{2}{|c|}{ Psychological } \\
\hline & OR & OR & $\mathrm{aOR}$ & OR & $\mathrm{aOR}$ \\
\hline Public & 1 & 1 & & 1 & 1 \\
\hline Private & $1.0(0.9-1.3)$ & $1.1(0.7-1.4)$ & & $1.7(1.2-2.7)$ & $1.3(1.2-1.6)$ \\
\hline Age (years) & & & & & \\
\hline $16-21$ & 1 & 1 & & 1 & \\
\hline $15-10$ & $1.0(0.8-1.3)$ & $1.2(0.9-1.5)$ & & $1.0(0.8-1.3)$ & \\
\hline Sex & & & & & \\
\hline Male & 1 & 1 & & 1 & \\
\hline Female & $0.3(0.2-0.4)$ & $1.0(0.8-1.4)$ & & $0.5(0.4-0.8)$ & $0.6(0.4-0.8)$ \\
\hline Class & & & & & \\
\hline SSS 1 & $1.1(0.7-1.3)$ & $1.2(0.9-1.9)$ & & $1.1(0.8-2.3)$ & \\
\hline SSS 2 & $1.1(0.8-1.7)$ & $1.0(0.9-1.7)$ & & $1.1(0.7-1.4)$ & \\
\hline SSS 3 & 1 & & & & \\
\hline Religion & & & & & \\
\hline Christianity & $1.0(0.9-1.2)$ & 1.1(0.9-1.2) & & $1.1(0.9-1.3)$ & \\
\hline Islam & 1 & 1 & & 1 & \\
\hline Type of Family & & & & & \\
\hline Polygamous & 1 & 1 & & 1 & \\
\hline Monogamous & $1.0(0.9-1.1)$ & $3.8(1.0-2.0)$ & & $1.0(0.9-1.1)$ & \\
\hline Inter-parental Violen & & & & & \\
\hline No & 1 & 1 & 1 & 1 & \\
\hline Yes & $1.0(0.8-1.3)$ & $1.5(1.3-1.7)$ & 1.5(1.3-1.7) & $1.8(1.6-2.2)$ & $1.6(1.4-2.0)$ \\
\hline In a relationship & & & & & \\
\hline No & 1 & 1 & & 1 & 1 \\
\hline Yes & $1.1(0.8-1.2)$ & $1.7 ; 1.2-2.4$ & $1.5 ; 1.2-2.2$ & 1.3(1.1-1.9) & $1.3(1.1-1.5)$ \\
\hline
\end{tabular}

\section{Factors Influencing Experience of Violence}

From Table 4, sex was the only significant predictor of experience of physical violence (OR 0.3, CI 0.2-0.4), females were less vulnerable to the violence. As regards experience of sexual violence, the significant predictors were:- witnessing parental intimate partner violence (aOR 1.5; 95\%CI 1.3-1.7) and being in a relationship (aOR 1.7; 95\%CI 1.2-2.4). Concerning psychological violence, being female was protective (aOR 0.6 ; 95\%CI 0.4-0.8). Other significant factors were:- witnessing violence between parents (aOR 1.6; 95\%CI 1.4-2.0) and being in a relationship (aOR 1.3; 95\%CI1.1-1.5).

\section{DISCUSSION}

A high proportion of students in both schools had experienced violence. This finding is similar to results from other studies which also found violence to be a common experience of students. ${ }^{1,2,5}$ This experience of violence was also common among school pupils in South Africa and Lebanon. ${ }^{18-20}$ The high levels of violence in schools may be a reflection of the rising incidence of violence in the society as a whole.
For example, the reports of the occurrence of religious, ethnic, criminal, and political violence have increased dramatically during the last decade in various parts of the country and in many countries as well. ${ }^{21,22}$

In addition, there have been more reports of brutality by law enforcement agents on civilians. ${ }^{23}$ The increase in communal violence invariably will be transferred to the home. Thirdly, the frequent exposure to violence on the media may inadvertently suggest to adolescents that it is an acceptable way of life and a way to settle disagreements.

Concerns have been raised that many parents spend too little time with their children because they are engaged in the labour market trying to make their livelihood. This unfortunately may undermine parental monitoring and support, leaving children vulnerable to engaging in risky behaviours, including violence. ${ }^{24}$

It is also possible that the students who were not interviewed because they did not have parental consent or because they refused to assent may have done so because they were victims of violence, therefore the true prevalence may actually be even higher. 
The similarity in the prevalence of GBV in both schools confirms that violence occurs in all settings irrespective of socio economic status. ${ }^{3}$ Violence might also have been fostered by individual and familial factors, as a substantial number of the students were in a relationship and admitted history of parental intimate partner violence.

Witnessing inter parental violence in childhood could lead to a normative understanding of violence, as violence is regarded as a fitting means of conflict resolution. ${ }^{3}$ Such boys are likely to be controlling and be violent to their spouse later in life, while such young women are more likely to tolerate violence from their partners and respond in a passive way. Thus these silent observers play a role in propagating violence by either being victims or perpetrators of abuse. ${ }^{3}$

As regards types of violence, psychological violence was the commonest form of violence experienced. Similarly, other studies have found psychological violence to be commonest form of violence to students because its perpetration may be subtle and hidden from others., ${ }^{9,18}$ Some students had experienced the different types of violence concurrently. Researchers have observed that physical violence is often accompanied by psychological abuse, and in one third to over one half of cases by sexual abuse as well. ${ }^{3,19}$ The true prevalence of the sexual forms of violence is likely to be higher as some students might have denied the experience out of fear of stigma, and shame. ${ }^{19}$

Males and females were equally vulnerable to sexual violence. This is surprising as female students are usually more likely to experience or report involvement in coercive sex compared to males. ${ }^{3,25}$ It may also suggest that hitherto males may have underreported their experience of violence to maintain masculinity, but now feel more comfortable to admit history of violence. A substantial proportion of perpetrators of sexual violence were partners.

The prevalence of rape in both groups of students was higher than the $5.5 \%$ and $5.7 \%$ respectively found among out of school youth in Ibadan, Nigeria. ${ }^{14,26}$ It was also higher than the national prevalence of sexual violence for 15 to 19 years old, which was $6.6 \%{ }^{7}$ A similar prevalence have been reported by other authors. ${ }^{12,27}$ In Nigeria, rape is an offence punishable by life imprisonment. $^{28}$

Thus, there is the need for school-based interventions to educate students on how to avoid gender-based violence. Victims also need to be educated on how to cope and where to seek help following abuse.
The strength of this study was that both public and private school students were selected; also both male and female students were interviewed. The study is limited because of social desirability bias which could have occurred since data was collected by face to face interviews. Thus students might have answered according to social acceptance or left out important information out of fear of the repercussion or shame.

However, despite these limitations the results of the study has external validity and can be generalized to most secondary schools in Ilorin. Future research targeting students should assess violence perpetration.

\section{CONCLUSION}

GBV was a common problem experienced by both public and private senior secondary school students. Physical and psychological violence was more common among respondents in private schools, while sexual violence was more common in public schools. Experience of physical and psychological violence was significantly higher among male respondents; however experience of sexual violence was not significantly different between the sexes. GBV education programs directed at parents and students are urgently required in both public and privates schools.

The family and the school environment impacted on student's exposure to violence. The policy implication of this finding is directed at these two different dimensions. First, there is an urgent need for parents to acquire education on good parenting skills. Parents are important role models who can influence their children's violence-risk behaviours, therefore engaging them to enable them appreciate the consequences of their actions is crucial.

Parents who perpetrate or experience intimate partner violence should be referred for counselling and support. Parents should also monitor their children's behaviour at school. Secondly, school based intervention programmes to enable students acquire knowledge and skills that will enable them prevent violence and its consequences is crucial. These programmes should be developed in collaboration with the youth.

Perpetrators need to be counselled on how to resolve disputes without resorting to violence. In addition, teachers and school authorities will also benefit from sensitization on gender-based violence and non-violent conflict resolution methods to enable them reinforce these messages. The parents-teachers association meetings may provide the opportunity to implement some of these programmes. 


\section{ACKNOWLEDGEMENT}

We wish to acknowledge the administration of the schools for their support.

\section{REFERENCES}

1. Pulido VR, Martín SG, Lucas MB. Risk profiles and peer violence in the context of school and leisure time. Span J Psychgy 2011 Nov;14(2):701-11.

2. Castro Mde L, Cunha SS, Souza DP. Violence behavior and factors associated among students of Central-West Brazil. Rev Saud Pub 2011 Dec;45(6):1054-61.

3. World Health Organization. World Report on Violence and Health. Krug E, Dalhberg L, Mercy J, Zwi A, Lozano R (Eds). WHO Geneva; 2002 Oct:3-21.

4. Scarpa A. Community violence exposure in young adults. TVA. 2003 Jul;4(3):210-27.

5. O'Donnell DA, Roberts WC, Schwab-Stone M. Community violence exposure and post-traumatic stress reactions among Gambian youth: the moderating role of positive school climate. Soc Psycht and Psycht Epid 2011 Jan;46(1):59-67.

6. Federal Ministry of Education. The national strategic framework for violence free basic education in Nigeria. 2007 Abuja: Federal Ministry of Education.

7. Nigeria National Population Commission (NPC) and ICF Macro. Nigeria Demographic and Health Survey 2003. Abuja, Nigeria: National Population Commission and ICF Macro;2004 Feb.

8. Mytton J, DiGuiseppi C, Gough D, Taylor R, Logan N. School-based secondary prevention programmes for preventing violence. Cochr Data Sys Rev 2006 Jul;2(19):3-8.

9. Arnold D, Gelaye B, Goshu M, Berhane Y, Williams MA. Prevalence and risk factors of genderbased violence among female college students in Awassa, Ethiopia. Vio Vict 2008 Feb;23(6):787800.

10. Ajuwon AJ, Fawole OI, Osungbade KO. Experience and Perpetration of Violent Behaviours among Secondary School Students in Ibadan, Nigeria. Sierra Leone J Biomed Res 2011, 3(1): 27-35.

11. Adefunke, ES. Types and prevalence of peer victimization among secondary school students in Osun State, Nigeria: Implications for counseling. Intl $J$ Cross-Disp Subj Educ 2010 Mar; 1 (1), 93-102.

12. National Population Commission (NPC). The 2006 National Census Report. National Population Commission, Abuja; 2007 Jun.

13. Kwara State Ministry of Education (KSME). Ministry of Education, Secretariat, Ibadan, Oyo state:10; 2010 Jun.
14. Fawole OI, Ajuwon AJ, Osungbade KO, Faweya CO. Prevalence and nature of violence to young female hawkers in motor parks in south western Nigeria. Health Educ Res. 2003 Apr;102(1); 230238.

15. Garcia-Moreno C, Jansen HA, Ellsberg M, Heise L, Watts CH. WHO Multi-country Study on Women's Health and Domestic Violence against Women Study Team. Prevalence of intimate partner violence: findings from the WHO multi-country study on women's health and domestic violence. Lancet 2006 Apr; 368:1260-9.

16. SPSS Inc. SPSS Base 9.0 for Windows User's Guide. SPSS Inc., Chicago. Nov1998.

17. World Health Organization. World Health Organization ethical and safety recommendations for researching, documenting and monitoring sexual violence in emergencies. World Health Organization, Geneva, Aug 2007.

18. El Bcheraoui C, Kouriye H, Adib SM. Physical and verbal /emotional abuse of school children in Lebanon, 2009. East Mediterr Health J 2012 Oct;18(10):101120.

19. CIET Africa. Sexual violence and HIV/AIDS: executive report on the 2002 survey. Project report PR-ZA-hn2-Feb 2002. Available at: www.ciet.org/en/documents/projects_library_docs/ 2006316174822.pdf (Accessed 11 July 2014).

20. Swart L.A., Seedat M., Stevens G. and Ricardo I. Violence in adolescents' romantic relationships: findings from a survey amongst school-going youth in a South African community. $J$ Adolescence, 2002 Sep ; 25(4):385-395

21. Settersten RA, Ray B. Whats going on with young people today? The long and twisting way to adulthood. Fut child 2010 Spring; 20(1):19-41.

22. United Nations. Population Division of the United Nations Secretariat, World Urbanization Prospects, Geneva Switzerland; 2010 May.

23. Udosen AM, Etiuma AU, Ugare GA, Bassey OO. Gunshot injuries in Calabar, Nigeria: an indication of increasing societal violence and police brutality. Afr Hlth Sc. 2006 Sep;6(3):170-

24. Ige OK, Fawole OI. Preventing child sexual abuse: parents' perceptions and practices in urban Nigeria. J Child Sex Abu 2011 Nov;20(6):695-707.

25. Fawole OI, Ajuwon AJ, Osungbade KO. Evaluation of interventions to prevent gender based violence among young female apprentices in Ibadan, Nigeria. Hlth Educ Res 2005 Mar;105(3):186-203.

26. Petersen I, Bhana A, McKay M. Sexual violence and youth in South Africa: the need for community based prevention interventions. Child $\mathrm{Abu} \mathrm{Neg}$ 2005 Nov;29:1233-1248. 
27. Okoro FI, Osawemen O. Sexual Harassment: The Experience of out-of-school Teenagers in Benin City, Nigeria. Afr J Rep Hlth 2009 Dec;9(3):118127
28. Federal Government of Nigeria (FGN). The Nigerian Penal code section. Criminal Justice system of Oyo State, Ibadan, 1963 Mar;55(1):d. 